\title{
The Mutation in the Mitochondrial Aldehyde Dehydrogenase (ALDH2) Gene Responsible for Alcohol-induced Flushing Increases Turnover of the Enzyme Tetramers in a Dominant Fashion
}

\author{
Qing Xiao, Henry Weiner, ${ }^{*}$ and David W. Crabb \\ Departments of Medicine and Biochemistry and Molecular Biology, Indiana University School of Medicine, Indianapolis, Indiana \\ 46202-5121; and *Department of Biochemistry, Purdue University, West Lafayette, Indiana 47907
}

\begin{abstract}
Deficiency in mitochondrial aldehyde dehydrogenase (ALDH2), a tetrameric enzyme, results from inheriting one or two $A L D H 2 * 2$ alleles. This allele encodes a protein subunit with a lysine for glutamate substitution at position 487 and is dominant over the wild-type allele, $A L D H 2 * 1$. The $A L D H 2 * 2$-encoded subunit (ALDH2K) reduces the activity of ALDH2 enzyme in cell lines expressing the wild-type subunit (ALDH2E). In addition to this effect on the enzyme activity, we now report that $A L D H 2 * 2$ heterozygotes had lower levels of ALDH2 immunoreactive protein in autopsy liver samples. The half-lives of ALDH2 protein in HeLa cell lines expressing $A L D H 2 * 1, A L D H 2 * 2$, or both were determined by the rate of loss of immunoreactive protein after inhibition of protein synthesis with puromycin and by pulsechase experiments. By either measure, ALDH2E enzyme was very stable, with a half-life of at least $22 \mathrm{~h}$. ALDH2K enzyme had an enzyme half-life of only $14 \mathrm{~h}$. In cells expressing both subunits, most of the subunits assemble as heterotetramers, and these enzymes had a half-life of $\mathbf{1 3} \mathrm{h}$. Thus, the effect of ALDH2K on enzyme turnover is dominant. These studies indicate that the $A L D H 2 * 2$ allele exerts its dominant effect both by interfering with the catalytic activity of the enzyme and by increasing its turnover. This represents the first example of a dominantly acting allele with this effect on a mitochondrial enzyme's turnover. ( $J$. Clin. Invest. 1996. 98:2027-2032.) Key words: aldehyde • ethanol • enzyme $\cdot$ liver $\cdot$ protein degradation
\end{abstract}

\section{Introduction}

The well-known alcohol-induced flush reaction is caused by a mutation in the structural gene for the mitochondrial aldehyde dehydrogenase $(\mathrm{ALDH} 2)^{1}(1,2)$. The variant allele, desig-

\footnotetext{
Address correspondence to David Crabb, Departments of Medicine and Biochemistry and Molecular Biology, Indiana University School of Medicine, IB 424 Medical Research and Library Building, 975 West Walnut Street, Indianapolis, IN 46202-5121. Phone: 317-2743122; FAX: 317-274-3106; E-mail: dcrabb@medicine.dmed.iupui.edu

Received for publication 6 June 1996 and accepted in revised form 26 August 1996.
}

1. Abbreviations used in this paper: $\mathrm{ALDH} 2$, mitochondrial aldehyde dehydrogenase; ALDH2E, active ALDH2 with a glutamate at position 487; ALDH2K, ALDH2 variant with lysine at position 487.

The Journal of Clinical Investigation

Volume 98, Number 9, November 1996, 2027-2032 nated $A L D H 2 * 2$, encodes a lysine for glutamate substitution at residue 487 of the mature enzyme $(3,4)$. The protein encoded by this allele, named ALDH2K for the amino acid substitution, had a markedly increased $K_{\mathrm{m}}$ for NAD ${ }^{+}$and reduced $V_{\max }$ when expressed as homotetramers in a bacterial expression system (5). This change in $K_{\mathrm{m}}$ for $\mathrm{NAD}^{+}$renders the enzyme nearly inactive at the concentration of $\mathrm{NAD}^{+}$that occurs in cells. Moreover, heterozygous individuals, in whom various heterotetramers of ALDH2K and normal ALDH2E subunits are present, are deficient in ALDH2 activity as well (6). The dominance is not complete, as heterozygotes have a milder flush reaction than $A L D H 2 * 2$ homozygotes (7).

This dominant effect was confirmed recently by this laboratory using retrovirally transduced cell lines expressing one or both alleles. Introduction of the $A L D H 2 * 2$ cDNA into cells expressing $A L D H 2 * 1$ resulted in a reduction in enzyme activity. It was assumed that the subunits associated randomly. The degree of reduction in activity in cell lines expressing varying ratios of the $\mathrm{ALDH} 2 \mathrm{E}$ and $\mathrm{ALDH} 2 \mathrm{~K}$ subunits was fit to a model in which only ALDH2E tetramers and $(\mathrm{ALDH} 2 \mathrm{E})_{3^{-}}$ $(\mathrm{ALDH} 2 \mathrm{~K})_{1}$ heterotetramers were enzymatically active, with the normal tetramer having two active sites per subunit and the heterotetramer having one active site (6). Other tetramers containing more ALDH2K subunits were apparently inactive under the assay conditions used. This model accounted for a substantial dominant effect of $A L D H 2 * 2$, predicting that the heterozygotes would have $\sim 18 \%$ of the normal activity in livers of homozygotes.

However, this model did not account for the absence of ALDH 2 activity observed with liver extracts from $A L D H 2 * 2$ heterozygotes analyzed by electrophoresis and staining for enzyme activity. Therefore, additional mechanisms to explain the low ALDH activity were sought. It was noted that in the cells expressing both $A L D H 2$ alleles, the total amount of ALDH2 protein detected by quantitative Western blots was lower than expected (ranging from 1.2 to 2 times that of the cells expressing only ALDH2E from which the doubly transduced cells were derived) (6). In addition, studies performed before the genetic basis for the deficiency was understood suggested that liver extracts from individuals deficient in ALDH2 activity had less immunologically cross-reactive ALDH2 protein than individuals with active ALDH2 $(8,9)$. Preliminary measures of the enzymes' half-lives in the transduced HeLa cells suggested no difference between ALDH2E and ALDH2K (6). However, the method used tends to underestimate the half-life of metabolically stable proteins. Therefore, we have extended the preliminary observations by Western blotting liver extracts to determine ALDH2 protein levels and by measuring the turnover of the enzyme in the ALDH2-expressing cell lines by a combination of approaches. We now report a dominant effect of the ALDH2K subunit on the turnover of the enzyme. 


\section{Methods}

Most chemicals were from Sigma Chemical Co. (St. Louis, MO). Antibodies directed against 3-hydroxyisobutyrate dehydrogenase were kindly provided by Dr. Robert Harris (Indiana University). Radioactively labeled cysteine and methionine $\left({ }^{35} \mathrm{~S}\right.$-Translabel) and ${ }^{125} \mathrm{I}$-labeled protein A were from ICN Biochemicals, Inc. (Irvine, CA). Liver samples were provided by Dr. T.-K. Li and Dr. William Bosron (Indiana University) and were genotyped at the $A L D H 2$ locus (10) by the Molecular Biology Core of the Indiana Alcohol Research Center.

Cell lines and culture conditions. The retrovirally transduced cells used for this study were described previously (6). They were maintained in minimal essential medium with $5 \%$ fetal calf serum, $100 \mu \mathrm{g}$ streptomycin/ml, and $63 \mu \mathrm{g}$ penicillin $\mathrm{G} / \mathrm{ml}$. For determination of protein degradation rates, the cells were split and grown overnight. In the morning, puromycin $(100 \mu \mathrm{g} / \mathrm{ml})$ was added. The zero time cells were harvested $30 \mathrm{~min}$ later, and cells were subsequently harvested 4 , $8,16,20$, and $24 \mathrm{~h}$ later. The cells were rinsed, scraped into $1 \mathrm{ml}$ of phosphate-buffered saline, and centrifuged at $14,000 \mathrm{~g}$ for $2 \mathrm{~min}$. The cell pellets were frozen at $-80^{\circ} \mathrm{C}$ until analysis. Cell proteins were extracted by suspending them in $50 \mathrm{mM}$ sodium phosphate, $\mathrm{pH} 6.0,1 \%$ Triton X-100, $1 \mathrm{mM}$ PMSF, $1 \mathrm{mM}$ dithiothreitol, and $1 \mathrm{mM}$ EDTA, then briefly sonicating them on ice. The suspension was then centrifuged for $10 \mathrm{~min}$ at $14,000 \mathrm{~g}$ and the supernatant was used for quantitative Western blotting as described previously (6). Standard curves had been shown previously to be linear in this range of protein loading.

Analysis of ALDH2 levels in human liver samples. Autopsy liver samples were stored at $-80^{\circ} \mathrm{C}$ until use. $100-\mathrm{mg}$ samples of frozen liver were homogenized in a Polytron homogenizer in the cell extraction buffer. The homogenate was then centrifuged at 100,000 $\mathrm{g}$ for $1 \mathrm{~h}$. The supernatants were analyzed by isoelectric focusing and Western blotting as described (6). As an internal control for degradation of proteins, a separate aliquot of extract was fractionated by SDSPAGE and Western blotted with antiserum raised against 3-hydroxyisobutyrate dehydrogenase. The antibody bound to the proteins was visualized by incubating the blot with ${ }^{125} \mathrm{I}$-labeled protein $\mathrm{A}$, followed by washing and autoradiography. The blots were quantified by $\beta$-scanning the filters. The radioactivity in the bands was corrected for background by subtracting the average radioactivity in the same area of the filter above and below the band.

Pulse-chase labeling. Cells were replated $1 \mathrm{~d}$ before the experiment and used the following morning at a density of $1.5 \times 10^{6}$ cells per $60-\mathrm{mm}$ dish. The cells were first incubated in cysteine- and methionine-free medium to deplete intracellular amino acid pools. They were then incubated with $40 \mu \mathrm{Ci}$ of ${ }^{35} \mathrm{~S}$-Translabel (a mixture of ${ }^{35} \mathrm{~S}$-labeled methionine and cysteine derived from Escherichia coli lysates) in $0.4 \mathrm{ml}$ of cysteine- and methionine-free medium for various times. Biosynthetic rates were determined by harvesting the cells at 1 , 2,4 , and $8 \mathrm{~h}$ and determining the incorporation of label into immunoprecipitable ALDH2. Degradation rates were determined by labeling the cells for $8 \mathrm{~h}$, then rinsing the cells repeatedly to remove the labeled amino acids, and culturing them for varying times in standard medium. Immunoprecipitations were carried out by incubating $20 \mu \mathrm{g}$ of cell extract (prepared as above) with $10 \mu$ l of preimmune serum for $2 \mathrm{~h}$ at $4^{\circ} \mathrm{C}$. Nonspecifically bound proteins were removed with $20 \mu \mathrm{l}$ of protein A Fast Flow-4. Supernatants were then incubated with $2 \mu \mathrm{g}$ of purified anti-ALDH 2 antibody for $8 \mathrm{~h}$. The immune complexes were then recovered by adding $20 \mu \mathrm{l}$ of protein A FastFlow- 4 and incubating an additional $1 \mathrm{~h}$. The complexes were pelleted at 14,000 $\mathrm{g}$ and were washed three times with $1 \mathrm{ml}$ of the immunoprecipitation buffer. The entire pellet was then denatured and the supernatant was analyzed by SDS-PAGE (11). The gels were dried and the radioactivity in the bands was quantified by $\beta$-scanning.

Statistical analysis. Differences in the amounts of ALDH2 in livers of different genotypes as well as in rates of protein synthesis or degradation were determined by ANOVA (SPSS Inc., Chicago, IL). Degradation and synthetic rates were determined by least-squares fits of the logarithm of counts per minute in the ALDH2 bands plotted against time (12), using Microsoft Excel.

\section{Results}

Levels of ALDH2 immunoreactivity in human liver samples. Polyclonal antibodies were generated against purified bovine liver ALDH2. The antibodies were characterized by Western blotting different amounts of extracts of ALDH2E- and ALDH2K-expressing cells, developing the blot with the antibodies and radiolabeled protein $\mathrm{A}$, and quantifying the radioactivity in the bands with a $\beta$-scanner (similar to the first three lanes of Fig. $1 A$ ). The slopes of the plots of radioactivity per band versus the amount of protein loaded were the same for ALDH2E and ALDH2K (not shown), indicating that the antibodies detected ALDH2E and ALDH2K proteins equally well. 13 human liver samples were genotyped at the $A L D H 2$ locus, and protein extracts were analyzed by quantitative Western blotting of isoelectric focusing gels. Fig. $1 A$ shows a representative Western blot. Equal amounts of protein were loaded for each individual. The isoelectric points of the proteins confirmed the genotypes in each case. The intensity of the bands suggested that the level of ALDH2 immunoreactive material was higher in the $A L D H 2 * 1$ homozygotes than in heterozygotes. Since only a single $A L D H 2 * 2$ homozygous

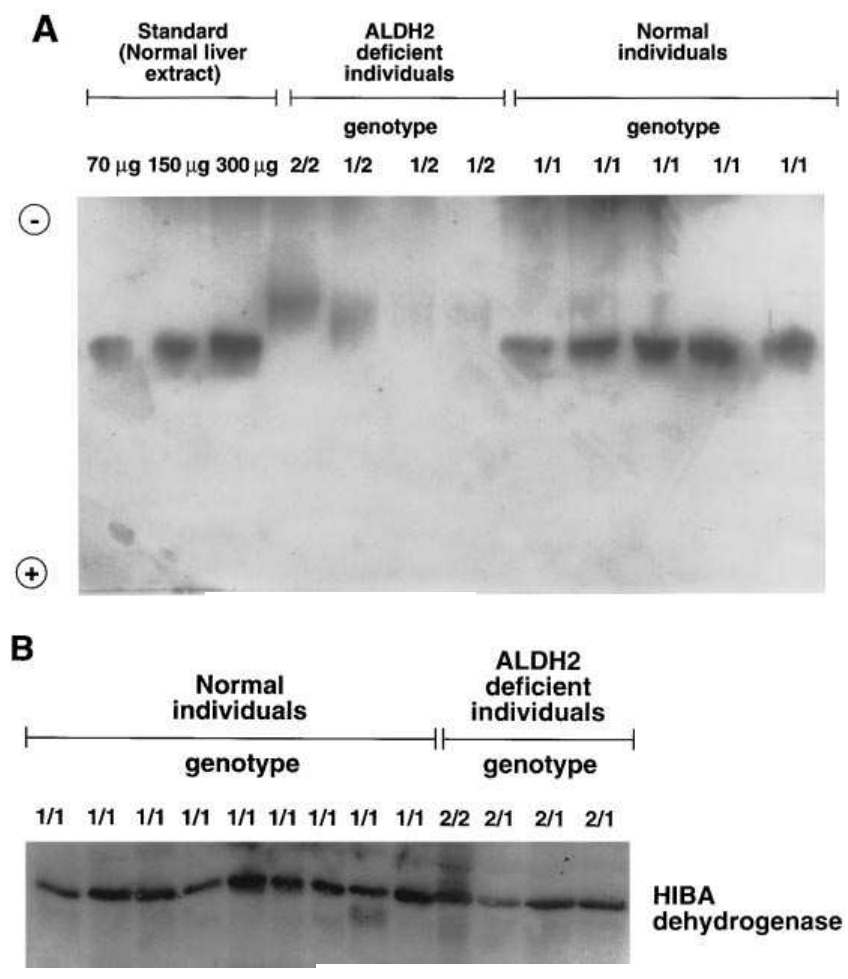

Figure 1. Levels of immunoreactive ALDH2 and 3-hydroxyisobutyrate dehydrogenase in autopsy human liver samples. $(A)$ Autoradiogram of a Western blot of an agarose isoelectric focusing gel. The first three lanes were included to demonstrate the linearity of the assay. ALDH2 genotype was determined by a PCR-based method (10). Enzyme containing ALDH2K subunits migrated more cathodally. (B) Autoradiogram of an SDS-PAGE Western blot of liver extracts developed with antibody raised against 3-hydroxyisobutyrate (HIBA) dehydrogenase. 
liver was available for analysis, it was impossible to determine differences in enzyme protein levels between $A L D H 2 * 2$ hetero- and homozygotes.

A possible explanation for the lower amount of ALDH2 seen in the heterozygotes was random differences in postmortem degradation of proteins. A control for this possibility was determination of the level of another mitochondrial matrix space protein. Therefore, Western blots were performed to assess the levels of 3-hydroxyisobutyrate dehydrogenase, a matrix space enzyme involved in valine catabolism (Fig. $1 B$ ). These blots showed relatively constant levels of this protein from liver to liver. The Western blots were quantified using a $\beta$-scanner. The radioactivity in the $A L D H 2 * 1$ homozygote extracts was $540 \pm 60 \mathrm{cpm} /$ band (means $\pm \mathrm{SE}, n=9$ ), while that in the $A L D H 2 * 2$ group was $240 \pm 10 \mathrm{cpm} /$ band $(n=4, P<0.02)$. The level of 3-hydroxyisobutyrate dehydrogenase was $490 \pm 40$ and $450 \pm 70 \mathrm{cpm} / \mathrm{band}$, respectively $(P=0.64)$. The ratios of ALDH2 to HIBA were $1.2 \pm 0.2$ and $0.6 \pm 0.1$ (means \pm SE) for the normal versus ALDH2-deficient groups. Thus, livers from $A L D H 2 * 2$ hetero- or homozygotes had about half the ALDH2 protein level of the livers with active ALDH2.

Turnover of ALDH2 isozymes in transduced cell lines. There are no hepatoma or other cell lines that express $A L D H 2 * 2$; therefore, cell lines expressing one or both $A L D H 2$ alleles previously constructed in the laboratory were used (6). In addition to cells transduced with only $A L D H 2 * 1$ or $A L D H 2 * 2$ expressing vectors, one cell line (HeLa EK12) was selected for further study. It represents the situation predicted in heterozygous liver cells, since it expressed equal levels of $A L D H 2 * 1$ and $A L D H 2 * 2$ transcripts. These cells were shown previously to form heteromeric enzymes with isoelectric points between those of ALDH2E and ALDH2K (6). ALDH2 protein was found at the highest level in the mito-


E cells

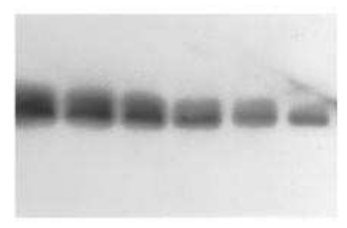

EK cells

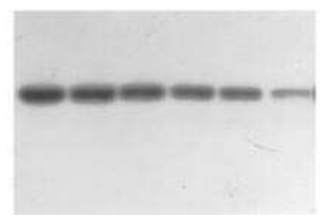

chondrial fraction of these cells prepared by sucrose gradient centrifugation and by immunocytochemistry (data not shown) and the ALDH2E and ALDH2K enzymes had the same $\mathrm{pI}$ as the liver enzymes, indicating that the ALDH2 subunits are correctly transported into and processed in the mitochondria. Thus, they are a reasonable model for the study of ALDH2 turnover.

The first approach taken was to follow the level of ALDH2 protein in cells treated with puromycin. In the absence of new protein synthesis, the decline in protein levels reflects the rate of degradation. The cells were cultured for 4-24 $\mathrm{h}$ after the addition of puromycin at a concentration reported to completely inhibit protein synthesis (13), and extracts of the cells were Western blotted to quantify the level of ALDH2 protein remaining (Fig. 2). Longer periods of incubation were not possible due to the toxicity of puromycin. Originally, we had reported that the half-life of ALDH2E was $26 \mathrm{~h}$ (6). With additional experiments, the estimated half-life was $53 \pm 21 \mathrm{~h}$ ( $n=6$ replicate experiments). The large standard deviation reflects the inaccuracy in determining the small changes in protein level over $24 \mathrm{~h}$ for a stable protein, since the fitting of data is disproportionately affected by the $24 \mathrm{~h}$ time point. On the other hand, the half-life of the ALDH2K-containing proteins was $16 \pm 3 \mathrm{~h}(n=5)$ for cells containing heterotetramers, and $19 \pm 6 \mathrm{~h}(n=6)$ for cells containing homotetrameric ALDH2K (the latter similar to our initial estimate of $24 \mathrm{~h} \mathrm{[6]).} \mathrm{These} \mathrm{two}$ half-lives were significantly less than that for ALDH2E $(P<$ $0.005)$, but were not significantly different from each other.

To obviate the problems inherent in inhibitor studies, the biosynthetic rate and half-life of the proteins were then determined by pulse-chase experiments. Results of a representative experiment are shown in Fig. $3 A$. During the pulse phase, the rate of incorporation of label into immunoprecipitable ALDH2 was not significantly different for the three cell lines. During the chase with unlabeled amino acids, the rate of loss of radioactivity was greater for $A L D H 2 * 2$-expressing cells (HeLa CK and HeLa EK) than in the cells expressing only $A L D H 2 * 1$ (Fig. $3 B$ ). The half-lives estimated from this method were $22 \pm 8 \mathrm{~h}$ for ALDH2E $(n=5), 14 \pm 5 \mathrm{~h}$ for ALDH2K $(n=3)$, and $13 \pm 4 \mathrm{~h}$ for cells expressing both subunits $(n=5, P<0.05)$. These results are summarized in Table I.

Table I. Turnover of ALDH2 Subunits in HeLa Cells

\begin{tabular}{llll}
\hline & \multicolumn{2}{c}{ Protein half-life (h) } & \\
\cline { 2 - 3 } Cell line & Puromycin decay & Pulse-chase & $\begin{array}{c}\text { Synthetic rate (cpm/h) } \\
\text { pulse label }\end{array}$ \\
\hline HeLa CE & $53 \pm 21(6)$ & $22 \pm 8(5)$ & $250 \pm 90(4)$ \\
HeLa EK & $16 \pm 3(5)^{*}$ & $13 \pm 4(5)^{*}$ & $310 \pm 140(4)$ \\
HeLa CK & $19 \pm 6(6)^{*}$ & $14 \pm 5(3)^{*}$ & $220 \pm 40(4)$ \\
\hline
\end{tabular}

The cells lines were clonal lines expressing ALDH2E (HeLa CE), ALDH2K (HeLa CK), or both subunits (HeLa EK) (6). Decay in protein mass after puromycin was determined by Western blotting. Decay in protein mass in the pulse-chase experiments was determined from loss of immunoprecipitable labeled ALDH2, and synthetic rate was determined as the increase in immunoprecipitable labeled ALDH2. The number of separate experiments is shown in parentheses, and the data given are means \pm standard deviation. *Statistically significant differences from the HeLa CE cells by ANOVA $(P<0.05)$. 


\section{A hours of pulse-label}
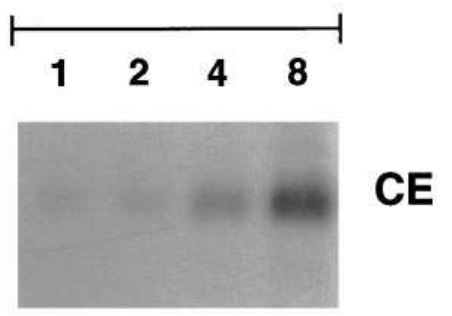

B
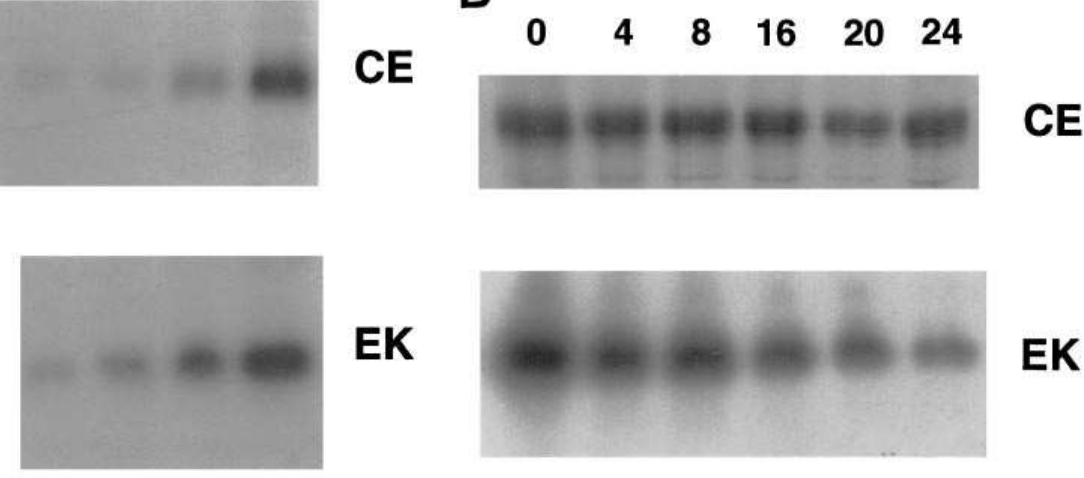

EK

Figure 3. Pulse experiments to determine turnover of ALDH2 subunits. (A) HeLa $\mathrm{CE}, \mathrm{EK}$, or CK cells were metabolically labeled with $\left[{ }^{35} \mathrm{~S}\right]$ methionine and $\left[{ }^{35} \mathrm{~S}\right]$ cysteine for the noted times, then immunoprecipitated and fractionated on SDSPAGE gels. (B) After $8 \mathrm{~h}$ of labeling, the cells were thoroughly rinsed and cultured in the presence of unlabeled methionine and cysteine for the noted times. The cells were then harvested, and the ALDH2 was immunoprecipitated and fractionated on

\section{CK}

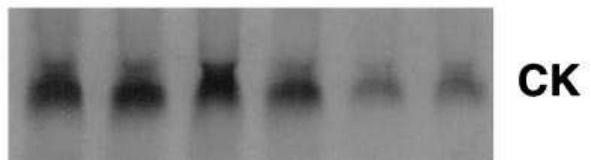
an SDS-PAGE gel. The radioactivity in the bands was quantified by $\beta$-scanning the gels.

Effect of increased turnover of $A L D H 2 K$ on expression of ALDH2 activity in heterozygotes. The effect of reduction in half-life on the residual activity of ALDH2 can be estimated from the amount of ALDH2K-containing tetramers predicted to be formed in heterozygous cells (Table II). Each ALDH2 allele directs synthesis of $n$ subunits; thus, there are $2 n / 4$ or $n / 2$ tetramers. If subunits assemble randomly, $6 \%(1 / 16)$ of the tetramers will be ALDH2E homotetramers with normal half-life. The remaining tetramers contain at least one ALDH2K subunit. The model that best accounted for the residual activity in cells expressing both alleles permitted two active sites for $\mathrm{E}_{4}$ and one active site for $\mathrm{E}_{3} \mathrm{~K}$ tetramers, predicting $37 \%$ residual activity (6). Table II shows the original model and corrections for the shorter half-life of heterotetramers (assumed here to result in a $50 \%$ reduction in protein levels). These models are compared with the activity expected for the parental cells expressing $n / 2$ active sites of ALDH2E (Table II). The reduced level of $\mathrm{E}_{3} \mathrm{~K}$ tetramers reduces the activity from 37 to $25 \%$, in reasonable agreement with observed residual activity $(31 \%$ of that in the ALDH2E-expressing cells from which the doubly transduced cells were derived [6]). If the reduction in $\mathrm{E}_{3} \mathrm{~K}$ subunits is $34 \%$ (based on the direct measurements in the HeLa cells), the agreement is even better (29\% activity predicted). The residual activity in heterozygous livers would be $12 \%$ of normal livers, since the acquisition of the $A L D H 2 * 2$ allele is accompanied by the loss of one of the $A L D H 2 * 1$ alleles. This is in the range of residual low $K_{\mathrm{m}} \mathrm{ALDH}$ activity reported in deficient human livers $(7,14)$.

\section{Discussion}

Human ALDH2 deficiency is an interesting genetic trait. From a clinical standpoint, it is the single strongest genetic factor that influences drinking behavior and risk of alcoholism (15-

Table II. Models for the Dominance of the ALDH2*2 Allele

\begin{tabular}{|c|c|c|c|c|c|}
\hline Enzyme tetramer & Fraction of total & Active sites per tetramer & Uncorrected active sites & Correction for half-life & Corrected active sites \\
\hline $\mathrm{E}_{4}$ & $1 / 16$ & 2 & $n / 16$ & $100 \%$ & $n / 16$ \\
\hline $\mathrm{E}_{3} \mathrm{~K}$ & $4 / 16$ & 1 & $2 n / 16$ & $50 \%$ & $n / 16$ \\
\hline $\mathrm{E}_{2} \mathrm{~K}_{2}$ & $6 / 16$ & 0 & 0 & $50 \%$ & 0 \\
\hline $\mathrm{EK}_{3}$ & $4 / 16$ & 0 & 0 & $50 \%$ & 0 \\
\hline \multirow[t]{3}{*}{$\mathrm{K}_{4}$} & $1 / 16$ & 0 & 0 & $50 \%$ & 0 \\
\hline & & & Sum: $3 n / 16$ & & Sum: $2 n / 16$ \\
\hline & & & $\%$ of parent cell: $37 \%$ & & $\%$ of parent cell: $25 \%$ \\
\hline
\end{tabular}

The calculations are based on the model presented previously (6) for ALDH2 heterotetramers. This model permits two active sites for $\mathrm{E}_{4}$ and one active site for $\mathrm{E}_{3} \mathrm{~K}$ tetramers and assumes synthesis of $n$ subunits per allele; thus, there will be $2 n / 4(=n / 2)$ tetramers synthesized. This value is multiplied by the fraction of each tetramer and the number of active sites per tetramer to obtain the uncorrected number of active sites. The corrected number of active sites takes into account the increased turnover of the $\mathrm{E}_{3} \mathrm{~K}$ tetramers. For comparison, the parental cells expressing only one $A L D H 2 * 1$ allele will synthesize $n$ submits, $n / 4$ tetramers, and therefore $n / 2$ active sites. Without the correction for turnover of the heterotetramer, the activity would be $37 \%$ of that of the parental cells ( $3 n / 16$ divided by $n / 2)$, and with the correction, $25 \%$ of the activity of the parental cells $(n / 8$ divided by $n / 2)$. 
17). At a more basic level, it results from a dominant negative mutation previously shown by this laboratory to alter the catalytic activity of the enzyme (6). However, the proposed model could not explain the virtual absence of ALDH2 activity on electrophoretograms of liver extracts from $A L D H 2 * 2$ heterozygotes, and additional mechanisms explaining the low activity in these livers were sought. Determination of the amount of ALDH2 protein in liver extracts demonstrated that $A L D H 2 * 2$ heterozygotes had about half the immunoreactive ALDH 2 protein found in $A L D H 2 * 1$ homozygotes. This difference did not result from nonspecific postmortem changes, since there was no difference between the two $A L D H 2$ genotypes in the levels of another mitochondrial dehydrogenase (3hydroxyisobutyrate dehydrogenase). Because $A L D H 2 * 2$ homozygotes are relatively rare, we were unable to determine if the reduction of ALDH2 protein was greater in those individuals than in heterozygotes, and we therefore examined ALDH2 turnover in a cell model.

First, the rate of disappearance of ALDH2 protein in the presence of puromycin was used to estimate the half-life of the protein. The ALDH2E enzyme had a half-life of $\sim 2 \mathrm{~d}$, but that of ALDH2K was significantly shorter at less than $24 \mathrm{~h}$. Pulse-chase labeling was then used to obtain a more accurate measure of the synthetic and degradative rate constants without the artifacts possible when protein synthesis inhibitors are present. The rate of incorporation of radioactive amino acids into ALDH2 was not significantly different between the three cell lines tested. A priori, one would predict higher rates of synthesis in the cells transduced with two $A L D H 2$ alleles, since two transcriptional units should be active. The cell line used here (HeLa EK12) had similar levels of $A L D H 2 * 1$ and $A L D H 2 * 2$ mRNAs, but the abundance of these mRNAs was lower than that of $A L D H 2 * 1$ mRNA present in the HeLa CE cells from which they were derived (6). Thus, similar rates of ALDH2 protein synthesis were consistent with the levels of mRNA previously determined in these cell lines.

The chase phase of this experiment clearly demonstrated that the ALDH2K-containing enzymes turned over faster than ALDH2E enzyme. Although the puromycin decay and pulsechase methods gave different absolute half-lives for the ALDH2E isozyme, the half-lives of the ALDH2K-containing isozymes were quite similar. This can probably be ascribed to the inaccuracy inherent in measuring the small changes in ALDH2E protein levels by Western blotting and to toxic effects of puromycin at the latter time points. Therefore, we believe the half-life for ALDH2E to be closer to $22 \mathrm{~h}$, as determined by the pulse-chase experiments. Since the half-life of ALDH2K homotetramers was reduced to the same extent as heterotetrameric enzyme, this effect of $A L D H 2 * 2$ is also dominant and suggests that the presence of a single ALDH2K subunit increases turnover of the enzyme. Increased turnover of the ALDH2K-containing enzyme contributes to the dominant effect of $A L D H 2 * 2$, but still does not explain the lack of activity seen on gel electrophoretic assays. It is possible that other phenomena, such as nonrandom association of the ALDH2E and $\mathrm{ALDH} 2 \mathrm{~K}$ subunits, also contribute to the phenotype. In particular, if the ALDH2E subunits associate preferentially with ALDH2K subunits (conceivably via formation of an intersubunit salt bridge between the normal glutamate and the variant lysine residues), the proposed models could account for nearly complete dominance.

These studies confirmed earlier observations of lower
ALDH2 protein in ALDH2-deficient livers $(8,9)$ by showing that ALDH2K-containing enzymes are degraded more rapidly than ALDH2E enzymes. The difference in half-lives between ALDH2E and ALDH2K enzymes determined here would result in a $34 \%$ reduction in total ALDH2 protein [taking into consideration the normal half-life of the small fraction of $(\mathrm{ALDH} 2 \mathrm{E})_{4}$ tetramers]. The difference between this value and the $50 \%$ reduction in $\mathrm{ALDH} 2$ in the liver extracts may simply reflect the well-known tissue-specific differences in enzyme degradation rates for the same protein (18). The mechanism by which ALDH2K exerts this effect is unknown. No difference in half-life of the two enzyme forms was apparent in $E$. coli expressing these proteins (5), suggesting that the difference relates to the subcellular compartmentation of ALDH2. Mitochondrial proteins are assisted in folding and in degradation by a family of heat shock proteins (19-22) and probably by a protease (PIM) characterized in yeast mitochondria (23). The ALDH2K subunit may slow the assembly of the tetramer and perhaps render it prone to more rapid catabolism. Such a mechanism has been demonstrated for medium chain acylCoA dehydrogenase mutants (24). Alternatively, the reduced affinity of the enzyme for $\mathrm{NAD}^{+}$may contribute to its higher turnover. The inhibition constant for $\mathrm{NAD}^{+}\left(\mathrm{K}_{\mathrm{ia}}\right.$, equivalent to the dissociation constant) for ALDH2E enzyme is $13 \mu \mathrm{M}$, whereas for the ALDH2K enzyme it is $\sim 500 \mu \mathrm{M}$, due to a much reduced rate of association of enzyme with coenzyme (5). Thus, at the estimated intramitochondrial-free $\mathrm{NAD}^{+}$concentration of $6 \mathrm{mM}$ (25), virtually all the wild-type enzyme would contain bound $\mathrm{NAD}^{+}$, whereas $\sim 8 \%$ of the ALDH2K enzyme would be coenzyme free, and potentially more liable to degradation. ALDH 2 heterotetramers synthesized in $E$. coli had only a single, rather low $K_{\mathrm{m}}$ for NAD ${ }^{+}$, but subunits without bound $\mathrm{NAD}^{+}$probably still are present in the heterotetramers (Wang, X., S. Sheikh, D. Saigal, L. Robinson, and H. Weiner, manuscript submitted for publication).

Increased turnover of mutant enzymes has been observed in numerous genetic diseases. In some cases the mutant enzyme is stabilized and enzyme activity is increased by supplementation of the diet with a vitamin precursor of the enzyme cofactor (for example, riboflavin for flavoproteins [26], pyridoxine for pyridoxal enzymes, and thiamine for thiamine pyrophosphate-dependent enzymes). These genetic deficiencies have invariably been recessively inherited. A possible exception is an unstable short chain acyl-CoA dehydrogenase in a compound heterozygote $(27,28)$, but it is not known if one allele was acting dominantly or if both alleles contributed to the instability. Certain porphyrias are dominantly inherited and three involve intramitochondrial enzymes, but these are examples in which a $50 \%$ reduction in enzyme activity is sufficient to cause the clinical phenotype, and the mutations are not dominant negatives. The $A L D H 2 * 2$ allele appears to be the first example of a dominantly acting mutation that alters turnover of a mitochondrial protein. It will be interesting to test whether manipulating mitochondrial $\mathrm{NAD}^{+}$levels modifies the half-life of the ALDH2K enzymes.

\section{Acknowledgments}

We are indebted to Dr. Robert Harris (Indiana University School of Medicine) for antisera against 3-hydroxyisobutyrate dehydrogenase. We appreciate the advice and comments of Drs. Mark Stewart, William Bosron, and Mats Estonius. 
This work was made possible by support for research from the American Liver Foundation to Qing Xiao, grants from the National Institute on Alcohol Abuse and Alcoholism (AA006434 and AA10525) to David W. Crabb, and the Indiana Alcohol Research Center (P50 AA 07611).

\section{References}

1. Harada, S., D.P. Agarwal, H.W. Goedde, S. Tagaki, and B. Ishikawa. 1982. Possible protective role against alcoholism for aldehyde dehydrogenase isozyme deficiency in Japan. Lancet. 2:827.

2. Goedde, H.W., S. Singh, D.P. Agarwal, G. Fritze, K. Stapel, and Y.K. Paik. 1989. Genotyping of mitochondrial aldehyde dehydrogenase in blood samples using allele-specific oligonucleotides: comparison with phenotyping in hair roots. Hum. Genet. 81:305-307.

3. Yoshida, A., I.-Y. Huang, and M. Ikawa. 1984. Molecular abnormality of an inactive aldehyde dehydrogenase variant commonly found in Orientals. Proc. Natl. Acad. Sci. USA. 81:258-261.

4. Hempel, J., R. Kaiser, and H. Jornvall. 1984. Human liver mitochondrial aldehyde dehydrogenase: a C-terminal segment positions and defines the structure corresponding to the one reported to differ in the Oriental enzyme variant. FEBS Lett. 173:367-373.

5. Farres, J., X. Wang, K. Takahashi, S.J. Cunningham, T.T. Wang, and H. Weiner. 1994. Effects of changing glutamate 487 to lysine in rat and human liver mitochondrial aldehyde dehydrogenase. J. Biol. Chem. 269:13854-13860.

6. Xiao, Q., H. Weiner, T. Johnston, and D.W. Crabb. 1995. The aldehyde dehydrogenase $A L D H 2 * 2$ allele exhibits dominance over $A L D H 2 * 1$ in transduced HeLa cells. J. Clin. Invest. 96:2180-2186.

7. Enomoto, N., S. Takase, M. Yasuhara, and A. Takada. 1991. Acetaldehyde metabolism in different aldehyde dehydrogenase 2 genotypes. Alcohol. Clin. Exp. Res. 15:141-144.

8. Impraim, C., G. Wang, and A. Yoshida. 1982. Structural mutation in a major human aldehyde dehydrogenase gene results in loss of enzyme activity. Am. J. Hum. Genet. 34:837-841.

9. Yoshida, A., G. Wang, and V. Dave. 1983. Determination of genotypes of human liver aldehyde dehydrogenase ALDH2 locus. Am. J. Hum. Genet. 35: $1107-1116$.

10. Crabb, D.W., H.J. Edenberg, W.F. Bosron, and T.-K. Li. 1989. Genotypes for aldehyde dehydrogenase deficiency and alcohol sensitivity. The inactive ALDH2*2 allele is dominant. J. Clin. Invest. 83:314-316.

11. Sastre, L., T.K. Kishimoto, C. Gee, T. Roberts, and T.A. Springer. 1986. The mouse leukocyte adhesion proteins Mac-1 and LFA-1: studies on mRNA translation and protein glycosylation with emphasis on Mac-1.J. Immunol. 137: 1060-1065.

12. Waterlow, J.C., P.J. Garlick, and D.J. Millward. 1978. Protein Turnover in Mammalian Tissues and in the Whole Body. Elsevier/North-Holland, Amsterdam.

13. Boren, J., L. Graham, M. Wettesten, J. Scott, A. White, and S.O. Olofsson. 1992. The assembly and secretion of ApoB 100-containing lipoproteins in HepG2 cells. ApoB 100 is cotranslationally integrated into lipoproteins. J. Biol.
Chem. 267:9858-9867.

14. Ferencz-Biro, K., and R. Pietruszko. 1984. Human aldehyde dehydrogenase: catalytic activity in Oriental liver. Biochem. Biophys. Res. Commun. 118 97-102.

15. Goedde, H.W., D.P. Agarwal, S. Harada, D. Meier-Tackmann, D Ruofo, U. Bienzle, A. Kroeger, and L. Hussein. 1983. Population genetic studies of aldehyde dehydrogenase isozyme deficiency and alcohol sensitivity. Am. J. Hum. Genet. 35:769-772.

16. Harada, S., D.P. Agarwal, H.W. Goedde, and B. Ishikawa. 1983. Aldehyde dehydrogenase isozyme variation and alcoholism in Japan. Pharmacol. Biochem. Behav. 18:151-153.

17. Thomasson, H.R., H.J. Edenberg, D.W. Crabb, X.-L. Mai, R.E. Jerome, T.-K. Li, S.-P. Wang, Y.-T. Lin, R.-B. Lu, and S.-J. Yin. 1991. Alcohol and aldehyde dehydrogenase genotypes and alcoholism in Chinese men. Am. J. Hum. Genet. 48:677-681.

18. Fritz, P.J., E.S. Vessell, E.L. White, and K.M. Pruitt. 1969. The roles of synthesis and degradation in determining tissue concentrations of lactate dehydrogenase. Proc. Natl. Acad. Sci. USA. 62:558-565.

19. Gething, M.J., and J. Sambrook. 1992. Protein folding in the cell. Nature (Lond.). 355:33-45.

20. Cyr, D.M., T. Langer, and M.G. Douglas. 1994. Dna-J-like proteins: molecular chaperones and specific regulators of Hsp 70. TIBS (Trends Biochem. Sci.). 19:176-181.

21. Cheng, M.Y., F.-U. Hartl, J. Martin, R.A. Pollock, F. Kalousek, W. Neupert, E.M. Hallberg, R.L. Hallberg, and A.L. Horwich. 1989. Mitochondrial heat-shock protein hsp60 is essential for assembly of proteins imported into yeast mitochondria. Nature (Lond.). 337:620-625.

22. Rowley, N., C. Prip-Buus, B. Westermann, C. Brown, E. Schwarz, B. Barrell, and W. Neupert. 1994. MDJ1p, a novel chaperone of the DnaJ family, is involved in mitochondrial biogenesis and protein folding. Cell. 77:249-258.

23. Wagner, I., H. Arlt, L.V. Dyck, T. Langer, and W. Neupert. 1994. Molecular chaperones cooperate with PIM1 protease in the degradation of misfolded proteins in mitochondria. EMBO (Eur. Mol. Biol. Organ.) J. 13:51355145 .

24. Saijo, T., W.J. Welch, and K. Tanaka. 1994. Intramitochondrial folding and assembly of medium chain acyl-coenzyme A dehydrogenase (MCAD). $J$. Biol. Chem. 269:4401-4408.

25. Tischler, M.E., D. Friedricks, K. Coll, and J.R. Williamson. 1977. Pyridine nucleotide distributions and enzyme mass action ratios in hepatocytes from fed and starved rats. Arch. Biochem. Biophys. 184:222-236.

26. Nagao, M., and K. Tanaka. 1992. FAD-dependent regulation of transcription, translation, post-translational processing, and post-processing stability of various mitochondrial acyl-CoA dehydrogenases and of electron transfer flavoproteins and the site of holoenzyme formation. J. Biol. Chem. 267:1792517932.

27. Naito, E., Y. Indo, and K. Tanaka. 1990. Identification of two variant short chain acyl-coenzyme A dehydrogenase alleles, each containing different point mutations in a patient with short chain acyl-coenzyme A dehydrogenase deficiency. J. Clin. Invest. 85:1575-1582.

28. Naito, E., Y. Indo, and K. Tanaka. 1989. Short chain acyl-coenzyme A dehydrogenase (SCAD) deficiency. J. Clin. Invest. 84:1671-1674. 